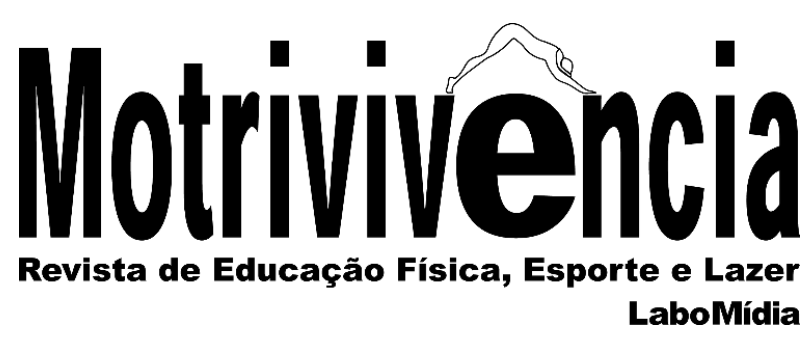

\title{
Uma análise das políticas públicas de lazer para a população LGBT em Belo Horizonte
}

\section{RESUMO}

O objetivo deste texto foi identificar as políticas públicas de lazer desenvolvidas por órgãos públicos representativos da população LGBT situados na cidade de Belo Horizonte, além de buscar compreender as perspectivas dos profissionais que atuam nesses locais sobre o lazer e a responsabilidade do órgão que representam em promovê-lo. Os resultados obtidos possibilitaram afirmar a existência de ações de lazer promovidas pelos órgãos estudados, mas identificamos que essas ações são pontuais e eventuais. Em relação à importância da promoção do acesso ao lazer, identificamos que alguns profissionais indicaram o lazer como pauta fundamental na organização de suas políticas e outros apontaram o lazer como um direito, mas com importância secundária.

PALAVRAS-CHAVE: Lazer; Políticas públicas; LGBT
Luiza Cupertino Xavier da Silva Bacharel em Educação Física Universidade Federal de Minas Gerais - UFMG Belo Horizonte, Minas Gerais, Brasil luiza.cupertino.xavier@gmail.com (ํ) https://orcid.org/0000-0001-8324-9159

Hélder Ferreira Isayama

Doutor em Educação Física Universidade Federal de Minas Gerais - UFMG

Departamento de Educação Física Belo Horizonte, Minas Gerais, Brasil Helderisayama@yahoo.com.br (D) https://orcid.org/ 0000-0002-4442-5356 


\title{
An analysis of leisure public policies for the LGBT population in Belo Horizonte
}

\begin{abstract}
The objective of this paper was to identify leisure developed by public bodies representing the LGBT population located in the city of Belo Horizonte, as well as to understand the perspectives of professionals working in these spaces about leisure and the responsibility of the agency they represent in promoting them. The obtained results made it possible to affirm the existence of leisure actions promoted by the studied organs, but we identified that these actions are punctual and occasional. Regarding the importance of promoting access to leisure, we identified that some professionals indicated leisure as a fundamental agenda in the organization of their policies and others pointed leisure as a right, but with secondary importance.
\end{abstract}

KEYWORDS: Leisure; Public policy; LGBT

\section{Análisis de las políticas públicas de ocio para la población LGBT en Belo Horizonte}

\section{RESUMEN}

El objetivo de este texto fue identificar políticas públicas de ocio desarrolladas por organismos públicos que representan a la población LGBT ubicada en la ciudad de Belo Horizonte, y tratar de comprender las perspectivas de los profesionales que trabajan en estos espacios sobre el ocio y la responsabilidad de la agencia que representan para promocionarlos. Los resultados obtenidos permitieron afirmar la existencia de acciones de ocio promovidas por los organismos estudiados, pero identificamos que estas acciones son puntuales y ocasionales. Con respecto a la importancia de promover el acceso al ocio, identificamos que algunos profesionales señalaron el ocio como una agenda fundamental en la organización de sus políticas y otros señalaron el ocio como un derecho, pero con una importancia secundaria.

PALABRAS-CLAVE: Ócio; Políticas públicas; LGBT 


\section{INTRODUÇÃO}

A Constituição Federal de 1988 estabelece, em seu artigo 6º , o lazer como direito social, o que é ainda salientado em seu artigo 217, ressaltando o papel do Estado na promoção às práticas de esporte e lazer. Neste artigo, vale ainda ressaltar o parágrafo $3^{\circ}$, que aponta para o papel do poder público em incentivar o lazer como forma de promoção social (BRASIL, 1988).

Marcellino (2001) aponta que a inclusão do lazer na Constituição representou um avanço no que se refere ao seu reconhecimento como direito social. No entanto, o autor faz uma crítica quanto à conotação do lazer no texto, entendendo que houve uma significação assistencialista da palavra. Nesse sentido, mesmo com os limites apresentados, a inclusão do lazer na Constituição teve importante papel no que se refere às medidas políticas que deveriam ser tomadas pelos governantes, uma vez que o lazer deixou de ser de um benefício social exclusivo dos trabalhadores ${ }^{1}$, tornando-se um direito necessário para a melhoria da qualidade de vida de todos os cidadãos e cidadãs (PINTO, 2008).

Para Cury (2006), o direito social deve ser assegurado pelo Estado, que deve evitar que haja uma progressão extrema por parte dos setores privados e deve ter como objetivo a redução das desigualdades, garantindo o acesso dos cidadãos e cidadãs aos bens sociais inerentes a uma vida digna. Para isso, cabe ao Estado desenvolver as chamadas políticas públicas. Segundo Souza (2002, p.5) “o processo de formulação de uma política pública é aquele através do qual os governos traduzem seus propósitos em programas e ações, que produzirão resultados ou as mudanças desejadas no mundo real".

Segundo Cury (2006), em países como o Brasil, caracterizado pela desigualdade social, em que somente as camadas privilegiadas possuem acesso a determinados bens sociais, é de suma importância a garantia de direitos em leis. Tais direitos poderiam, portanto, proporcionar ações e políticas públicas que visem à equiparação dos bens sociais, por meio de políticas inclusivas. Essas políticas deveriam ser propiciadas pelo Estado, a partir do princípio da igualdade de oportunidades e pela igualdade de todos ante a lei.

Por outro lado, há também o entendimento das políticas inclusivas, que possuem como estratégia a focalização de direitos para determinados grupos que são caracterizados como socialmente vulneráveis, seja por uma demanda histórica demarcada por processos de exclusão, ou por circunstâncias naturais que geraram algum tipo de deficiência àquele determinado grupo de indivíduos (CURY, 2006).

\footnotetext{
1 Anterior à Constituição de 1988, a partir da Consolidação das Leis de Trabalho (CLT), a possibilidade de desenvolvimento de políticas voltadas para o lazer era exclusivamente para os trabalhadores (PINTO, 2008).
} 
A focalização baseia-se, portanto, no princípio da equidade, por acreditar que as políticas universalistas não dão conta de gerar uma igualdade justa, devido à insuficiência de recursos. Dessa forma, a focalização de grupos específicos permitiria uma compensação/reparação de sequelas do passado.

De forma geral, temos de um lado a necessidade da defesa da igualdade no que diz respeito à garantia de direitos a todos os cidadãos e cidadãs: educação, saúde, segurança, lazer, entre outros. De outro, há uma inclusão à defesa de igualdade, da existência de uma marginalização social, fazendo-se necessária a equidade para gerar oportunidades iguais de acesso.

Nesse contexto, pensando no lazer como direito social estabelecido pela Constituição de 1988, o desafiou tornou-se a organização de projetos e políticas que pudessem consolidar esse direito acessível a todas e a todos, concebendo, assim, uma intervenção no campo do lazer que superasse a lógica social pautada na diferença e na desigualdade (MELO, 2003). Quando nos referimos a uma superação das diferenças e das desigualdades sociais, é necessário que a priori nos reportemos aos movimentos sociais, uma vez que, "muitas vezes correndo o risco de fragmentação da luta pela construção de uma nova ordem social, não podemos negar a importância e contribuições destes movimentos” (MELO, 2003, p. 24).

As lutas cravadas por essas minorias surtem efeitos também sobre o lazer dessas populações, uma vez que "o lazer é uma experiência cultural que não é apenas determinada mecanicamente pela base econômica, nem tampouco é livre e idealizada. É fruto de expressão ativa de relações sociais e das lutas que se estabelecem no cotidiano das camadas populares" (MELO, 2003, p. 55).

Há, então, nas pautas dessas minorias sociais, o acesso igualitário aos direitos sociais entre os quais o lazer. Exemplo dessa reivindicação pode ser constatado no Relatório Final da $3^{a}$ Conferência Nacional de Politicas Públicas de Direitos Humanos de Lésbicas, Gays, Bissexuais, Travestis Transexuais ${ }^{2}$, ocorrida no ano de 2016. No entanto, conforme apontado por Souza (2008), a sociedade é imbuída de contradições quando se trata da do acesso e a garantia de qualidade às necessidades humanas, uma vez que é uma sociedade demarcada pelos processos de exclusão e de controle sobre os corpos dos indivíduos, tendo-se como objetivo a manutenção de uma ordem social.

Essa ordem social, mencionada pela autora, acaba por gerar também ocupações distintas de territórios, espaços sociais e culturais, em que pobres e ricos, com exceção à produção cultural artística de massa, possuem acesso a distintos bens culturais e a diferentes espaços de lazer. Nesse

\footnotetext{
${ }^{2}$ No texto desse documento identificamos o lazer na pauta desse movimento de participação social em dois de seus eixos de discussão, o primeiro, Eixo I, intitulado Políticas Intersetoriais, Pacto Federativo, Participação Social e Sistema Nacional de Promoção da Cidadania e Enfrentamento da Violência Contra a População LGBT e o segundo, Eixo II, denominado Educação, Cultura e comunicação em Direitos Humanos (BRASIL, 2016).
} 
ponto, acreditamos que essa separação do acesso aos bens culturais e espaços de lazer ocorre para além de uma dicotomia pobre e rico; ela é inerente aos processos excludentes de nossa sociedade, que se dão pelos mais diversos fenômenos, na maioria deles os decorrentes de preconceitos e discriminações sociais.

Sendo assim, como uma tentativa de proporcionar uma possível equiparação no que diz respeito ao acesso ao lazer, é notório o crescimento dos chamados projetos sociais (MELO, 2009). Segundo o autor, esse quadro de crescimento dos números de projetos sociais se insurge dos mecanismos democráticos do País, em que se estabeleceu um novo conjunto de preocupações sociais.

No entanto, ao apontar o aumento da implementação de projetos sociais com as temáticas lazer e esporte, há que se realizar um adendo, pois muitos desses projetos ora surgem com propósitos de cunho assistencialista, ora se apresentam como projetos que a princípio possuem um discurso de inclusão, mas que, em contradição, implementam metodologias excludentes, em que são selecionados os mais aptos e desconsideram peculiaridades de determinados grupos, havendo assim uma exclusão entre os excluídos (MELO, 2009).

Essas políticas públicas assistencialistas, ainda segundo Souza (2008), possuem dois fatores característicos. O primeiro está relacionado à definição de uma categoria genérica entre os excluídos socialmente, que desconsidera "que são inúmeras as marcas histórico-culturais que constituem os processos excludentes" (SOUZA, 2008, p. 134). O segundo fator, segundo Souza (2008), faz referência à qualidade das propostas políticas e de sua implantação, por serem, geralmente, políticas de alívio a determinadas situações, mas que não transformam a realidade.

Conforme Monteiro (2009), o desafio é o de desenvolver políticas públicas de lazer que envolvam a relação do sujeito com o território. Trazendo neste momento à tona os equipamentos públicos de lazer, há de se ilustrar que eles estão condicionados às normas sociais e valores culturais que contribuem para um sentimento de pertencimento (MONTEIRO, 2009). Nesse sentido, conforme apontado por Marcellino (2008), há, nesses territórios de lazer, fatores limitadores a oportunidades de práticas de lazer, tais como a classe social, o nível de instrução, a faixa etária, o gênero, entre outros.

Há, portanto, uma legitimação social da discriminação dentro dos espaços de lazer, em que se entende que, uma vez que o Estado já oferece determinado serviço, cabe àquele sujeito se adaptar e não fracassar na sua "inserção" naquele "espaço disponível”, uma democratização cruel, que perpetua a exclusão dos direitos. Assim, para que seja possível pensar o lazer para as minorias sociais, é necessário um redimensionamento dos papéis sociais, que garanta a multiplicidade dos 
sujeitos e que não parta de uma tentativa de homogeneização, que negue a existência desses sujeitos (SOUZA, 2008).

Esse redimensionamento dos papéis sociais é de fundamental importância quando se trata do acesso ao lazer pelas minorias sociais, uma vez que é constatado que os sujeitos são excluídos de práticas devido a determinados marcadores identitários, sendo alvo de atitudes que os afastam das mais diversas atividades, uma vez que se sentem rejeitados pelos grupos e sujeitos dessas atividades (GOELLNER et al., 2009).

Nesse sentido, ao se pensar no lazer para minorias sociais, e especificamente para a população LGBT, é necessário que haja uma reflexão sobre qual cidadania pretendemos "instalar" em nossa sociedade. Qual seria o nosso objetivo? Criar uma forma de adequarmos os indivíduos ao modelo atual de uma sociedade que é pautada na desigualdade social ou contribuir para que as pessoas desenvolvam uma compreensão acerca do seu papel político, capaz de promover mudanças sociais concretas? É necessário que se coloque em pauta se o que é oferecido é um meio para se alcançar um fim "concreto" ou é algo oferecido sem articulação com o que se tem como objetivo (MELO, 2009).

Nessa perspectiva, Canabarro (2013), apontou que as discussões que abrangem questões como a sexualidade e política e suas formas de articulação vêm-se intensificando nos dias atuais. O autor nos lembra de que, no Brasil, no histórico da luta pelos direitos da população LGBT, tem-se como destaque o (re)aparecimento de diversos grupos denominados movimentos gays, durante a década de 1980, em concomitância ao início do processo de reabertura democrática.

Desde então, a partir da luta desses e de outros movimentos que agem em prol das causas LGBT, foram obtidas diversas conquistas. No entanto, apesar das vitórias alcançadas por essa população, conforme é destacado por Cabanarro (2013), a "homotransfobia" ainda se apresenta intensa em nossa sociedade, advinda de uma cultura caracterizada por uma heteronormatividade compulsória que "permite, recria e, até, incentiva, muitas vezes, a prática da injúria homotransfóbica e atos de violência" (CANABARRO, 2013).

Em relação à homofobia, um dos preconceitos vividos pela população LGBT, Fazzano e Gallo (2015, p. 544) afirmaram que "deixar o fenômeno da homofobia ao relento, sem preocupar-se cientificamente com o mesmo, é reafirmar o preconceito em suas diferentes formas e incidências". Acredita-se que essa afirmação deva ser ampliada e abranger os preconceitos provenientes da LGBTfobia, uma vez que essa população também enfrenta outros preconceitos específicos em relação à sua orientação sexual, tais como a bifobia e a lesbofobia. Além disso, é imprescindível ressaltar que este grupo é composto por indivíduos que são discriminados não somente por sua orientação sexual, mas também por questões relacionadas à identificação de gênero. 
Sob esse ponto de vista, tão importante quanto estudar o fenômeno da LGBTfobia em si é estudar as ações, sejam elas políticas ou não, que estão sendo organizadas em nossa sociedade que defrontem não somente os preconceitos em si, mas também os resultados degenerativos a uma minoria social que este proporciona. Entre essas ações e políticas, há que se garantir que a população LGBT seja pauta na elaboração das políticas públicas de lazer para a população.

Ao pesquisarmos na literatura trabalhos sobre as temáticas lazer, políticas públicas e população LGBT, nos deparamos com uma escassez de estudos que fazem a fusão desses três temas, tidos como "base" desta pesquisa. O que se verifica é que há carência na produção de trabalhos que tratem as políticas públicas de lazer que estão relacionadas à população LGBT. Além disso, Tavares e Isayama (2014) apontaram que as políticas de lazer encontradas são, em sua maioria, atividades que não conseguem trazer à sua aplicação reflexos sociais capazes de combater as desigualdades sociais.

É possível, então, identificar a importância e necessidade de compreendermos como o lazer está sendo tratado e desenvolvido na administração pública, ao mesmo tempo em que se observa um déficit de estudos que investiguem as políticas públicas/ações promovidas para a população LGBT.

Para realizar uma análise das políticas públicas de lazer voltadas para essa população, é necessário que, primeiramente, tenha-se a compreensão sobre como uma política pública é desenvolvida. É importante o entendimento de que o processo de elaboração de uma política é composto por diversas fases, que constituem o chamado ciclo de políticas públicas. Em relação a esse ciclo, Raeder (2014, p.128) o reconheceu a partir de cinco fases: (1) percepção e definição de problemas; (2) formação da agenda decisória; (3) formulação de programas e projetos; (4) implementação das políticas delineadas; (5) monitoramento e avaliação das ações planejadas. para a análise realizada neste estudo, buscamos identificar se há no desenvolvimento de políticas desses órgãos a inclusão do lazer nas três primeiras fases do ciclo de políticas públicas supracitado. Ou seja, se o acesso ao lazer pela população LGBT é percebido/definido como um problema, seguido de sua inclusão na formação da agenda decisória e da formulação de programas e projetos.

Visando contribuir para a produção científica desse tema, este trabalho tem como objetivo geral analisar as políticas públicas de lazer desenvolvidas por entidades públicas representativas da população LGBT presentes na cidade de Belo Horizonte. Para isso, o estudo teve como objetivos específicos indicar se há uma compreensão desses órgãos sobre sua responsabilidade e a importância em promover ações de lazer; analisar as concepções sobre o lazer desses profissionais e investigar se há ações de lazer desenvolvidas e, se sim, quais são as características das atividades de lazer propostas. 


\section{METODOLOGIA}

Esse estudo combinou as pesquisas bibliográfica, documental e de campo. Para a pesquisa de campo foram investigados os órgãos públicos, da administração pública direta, responsáveis pelo desenvolvimento de políticas públicas para o público LGBT que estão situados no município de Belo Horizonte.

Identificamos os seguintes órgãos: 1) Coordenadoria de Políticas para a População LGBT, da Prefeitura Municipal de Belo Horizonte, que atualmente é composta pela Diretoria de Políticas para a População LGBT (DLGBT) e pelo Centro de Referência LGBT (CRLGBT), vinculada à Secretaria Municipal de Assistência Social, Segurança Alimentar e Cidadania (SMASAC) e; 2) Coordenadoria Especial de Políticas de Diversidade Sexual do Governo do Estado de Minas Gerais, que no momento de realização da pesquisa integrava a estrutura da Secretaria de Estado de Direitos Humanos, Participação Social e Cidadania (SEDPAC).

Em relação ao método, foi realizada uma entrevista semiestruturada com os profissionais desses órgãos. No que concerne à definição da amostra, foi solicitado aos assessores, com quem mantínhamos contato, que fosse realizado o convite para a entrevista para todos os profissionais e, àqueles que se disponibilizassem, participariam da pesquisa. $\mathrm{Na}$ Coordenadoria municipal foi concedida a realização de uma entrevista que, a pedido dos próprios profissionais, foi realizada em conjunto com os dois entrevistados. $\mathrm{Na}$ Coordenadoria estadual quatro profissionais foram entrevistados e, também à pedido do órgão, uma das entrevistas foi realizada em dupla. Foram realizadas, portanto, um total de quatro entrevistas com seis profissionais.

Para a realização dessas entrevistas utilizamos um roteiro desenvolvido com base nas perguntas que se tinha como objetivo responder e foi previamente validado, por meio de uma entrevista-piloto realizada com um profissional do Centro de Luta pela Livre Orientação Sexual de Minas Gerais (Cellos). Nesse roteiro haviam perguntas que visavam a identificação das políticas promovidas pelos órgãos de forma geral e também, especificamente, das políticas de lazer e sobre a visão desses gestores em relação ao lazer e a da sua promoção.

Além disso, durante a realização das entrevistas foram indicados e concedidos pelos profissionais dois documentos que passaram por uma análise documental. Bardin (2009) aponta que esse processo da pesquisa tem como objetivo dar nova forma e representação a uma determinada informação através de um processo de transformação. Para o órgão estadual foi analisado o Relatório de Propostas da $3^{a}$ Conferência Estadual de Políticas Públicas e Direitos Humanos de $L G B T$. Em relação ao órgão municipal o documento investigado foi o Plano de trabalho da Coordenadoria. 
Para a análise dos dados, foi realizada a técnica de análise de conteúdo, seguindo as três etapas explicitadas por Bardin (2010), que são: a organização da análise, a codificação e a categorização.

\section{A identificação das políticas públicas dos órgãos e das políticas de lazer}

Primeiramente, nosso empenho foi em averiguar qual seria atualmente o principal foco e os principais objetivos das políticas desenvolvidas nos órgãos. Foi identificado que, em parte das falas dos profissionais, os focos apontados eram em relação à garantia dos direitos, assim como acerca da conscientização sobre esses direitos e sua visibilidade. Nesse sentido, surgiram as seguintes respostas: "garantir esse direito que, de alguma forma, não tá sendo garantido" (E2), "eu acho que o principal objetivo é disseminar o que a gente faz, e não só de uma forma para publicizar, mas orientar o cidadão mesmo, que ele tem direitos" (E3), "construir políticas de afirmação de igualdade e equidade" (E5), "dar mais visibilidade a pauta e suas necessidades" (E6).

Além disso, nas falas de outro profissional, ficou subentendida uma prioridade em relação às questões da transexualidade, embora tenham enfatizado que o órgão não possui um foco específico:

A gente trabalha com tanta coisa, a gente é preocupado com implementação do nome social, a gente é preocupado com a empregabilidade da população LGBT, com trans e travestis principalmente. A gente é preocupado com a questão prisional, da população LGBT que está presa e tantas outras coisas que a gente vai vendo, a gente faz convênios com outras entidades pra conseguir fundos ou pra ajudar na política também. Então o foco mesmo é difícil de responder um só, eu respondi alguns que eu me lembrei mas ainda tem mais, a gente não foca em uma coisa só, tem muita coisa que a gente vem trabalhando (E4).

Embora haja, de forma geral, na fala desses profissionais, a indicação de que os órgãos não possuem um foco específico para atuação, foi indicada por esses profissionais uma demanda maior em relação à pauta da transexualidade. Essa maior demanda em relação à essa população, aparece também em outros momentos das entrevistas, sempre apontando para o fato de essa ser a população que está sob maiores riscos sociais. Para um melhor entendimento acerca dessa questão, recorreu-se aos estudos de Silva et al. (2016), em que foi confirmada a perspectiva de que as travestis e os transexuais são no Brasil os principais alvos de violência na rua.

Outro ponto importante que pode ser observado é que, em meio à priorização do atendimento à população transexual e travesti, apontado pelos profissionais da coordenadoria estadual, pode-se identificar o aparecimento de uma ênfase para a questão do trabalho. Sobre esse apontamento, primeiramente, ressaltamos a dificuldade dessas pessoas em obter um emprego fora 
do mercado da prostituição, dada pelos mais diversos fatores, que vão desde o abandono familiar até a dificuldade de conclusão dos estudos, devido à falta de preparo do Estado (AMARAL, 2013). Nesse sentido, acreditamos que esse seja um dos pontos que tornem a discussão de políticas públicas, que garantam o acesso ao trabalho para essa população, tão presente.

No entanto, concomitantemente a essa questão, esse foco dado ao trabalho, também pode ser compreendido por meio de outra questão socialmente construída, que é a supremacia do direito social ao trabalho em nossa sociedade. Nesse contexto, é interessante que haja uma reflexão sobre o que aponta Lunardi (2015, p. 93):

Ao mesmo tempo em que estamos imersos em uma sociedade que tem como base o trabalho, vivemos a valorização da dignidade do ser humano, a valorização da saúde, do bem-estar, da prática de esportes, do convívio familiar, das inúmeras possibilidades de expressão artística, o que podemos definir como as atividades que uma pessoa pode realizar em seu período de lazer. Trata-se de um conflito em que está em jogo a necessidade do trabalho e o direito de ter a experiência plena da dignidade do ser humano.

Sobre esse conflito entre trabalho e lazer, o autor ainda afirma que, quando há um “desequilíbrio para qualquer um dos lados, estará sendo desrespeitado o outro direito" (LUNARDI, 2015, p. 93). Sendo assim, é fundamental haver um foco relacionado à questão do trabalho na atenção à população LGBT, contanto que haja também políticas e ações que pensem concomitantemente o acesso ao lazer para essa população e que, para além disso, possam abarcar as relações sociais que existem entre esses dois fenômenos.

Por fim, em relação à coordenadoria estadual algumas demandas das ações desenvolvidas pelo órgão são advindas de propostas que foram estabelecidas pela $3^{a}$ Conferência Estadual de Politicas Públicas e Direitos Humanos de LGBT, que ocorreu entre os dias 16 e 18 de outubro de 2015.

A partir da conferência, foi elaborado um Relatório de Propostas, o qual foi analisado objetivando identificar possíveis propostas acerca do lazer. O documento foi organizado a partir de quatro eixos temáticos para os quais foram afirmadas propostas em âmbito estadual e nacional. $\mathrm{Na}$ análise desse documento, pode-se identificar, no Eixo II, que tinha como tema a Educação, Cultura e Comunicação em Direitos Humanos, duas propostas de âmbito estadual que tiveram relação com o lazer:

1. Criar e implementar editais de chamamento público artístico e cultural específicos sobre a temática LGBT em âmbito estadual e nacional. (MINAS GERAIS, 2015, p.4).

2. Promoção e financiamento por parte do Estado de Minas Gerais, buscando parcerias com instituições de ensino federais e estaduais, de mostras artísticas, 
festivais de cinema e de dança, peças teatrais, produções literárias e outras expressões culturais diversas, com temáticas LGBT, com o intuito de fomentar e valorizar a visibilidade dessas expressões e a produção cultural local e para a promoção de seminários formativos com o intuito de capacitar e empoderar as lideranças e militâncias LGBT (MINAS GERAIS, 2015, p.5).

Nesse mesmo eixo, foi identificada uma proposta em âmbito nacional que tinha relação com o lazer: "Criar a Semana das Identidades e Diversidades LGBT juntamente com circuitos culturais (acadêmicos, artístico e esportivo) dentro do calendário escolar nas redes municipais, estaduais e federais" (MINAS GERAIS, 2015, p.5).

Sobre essas propostas, ressaltamos que elas foram classificadas dentro do contexto do lazer não somente pelo entendimento de que as atividades o proporcionarão especificamente, mas também pelo entendimento do lazer como "uma produção da cultura historicamente situada" (SILVA, 2015, p. 166). No entanto, há que se ressaltar que, conforme evidenciado por Santos e Amaral (2010), no que diz respeito às questões teórico-conceituais sobre lazer e políticas sociais, cabem algumas reflexões sobre o fato de as pessoas normalmente não denominarem as práticas culturais que vivenciam como lazer:

Essa distância da produção teórica em torno do lazer à sua presença na vida das pessoas - nos termos acima explicitados -, além de muito nos instigar, acarreta algumas complicações para a construção de políticas que o tenham como objeto como, por exemplo, a ausência de reivindicações populares por lazer que, por sua vez, leva à dificuldade de ele se legitimar como direito social e, consequentemente, como política social. Além disso, o debate de tal campo de estudos também se faz pouco presente no ciclo das políticas 2 de lazer que, muitas vezes, opera, em suas diferentes etapas, com concepções de lazer há muito superadas pelos estudos e pesquisas (SANTOS e AMARAL, 2010, p. 3).

A partir da análise do documento proveniente da conferência, há de se considerar que, pelo menos no que diz respeito às políticas públicas desenvolvidas pela coordenadoria estadual, as ações que fomentam o acesso ao lazer poderiam ser consideradas nas atividades desenvolvidas por esse órgão, uma vez que essas ações foram demandas pela população LGBT.

Aproveitando a análise desse documento que indicou a demanda por políticas que fazem relação com o lazer, foi questionado quais ações de lazer são desenvolvidas por ambas as coordenadorias. Para apresentação desses dados, foi realizada uma divisão das respostas obtidas entre a coordenadoria municipal e a coordenadoria estadual, para identificação e entendimento dessas ações.

Quanto à coordenadoria municipal, vale relembrar que a entrevista foi realizada com dois integrantes, sendo um representante do CRLGBT e o outro do DLGBT. Sendo assim, no caso do CRLGBT, foi apontado que, de forma geral, sua responsabilidade era apenas de, caso houvesse 
demanda em que o direito de acesso ao lazer estaria de alguma forma sendo violado para algum cidadão LGBT, garantir que esse direito fosse restituído. O profissional cita como exemplo um caso recorrente no Parque Municipal:

a agente tem feito algumas articulações junto a espaços de lazer com o parque municipal que as vezes é privado a permanência desses sujeitos nesses espaços, no ponto da sua condição, seja ela trans, seja ela lésbica, seja ela gay, que seja pelo uso do banheiro ou seja pela demonstração de afeto, ou pela população trans pelo simples fato de circular pelo espaço. Então a gente articula e conversa com esses espaços que são públicos, que de alguma forma as pessoas utilizam para fazer o seu lazer, pra que esse tipo de discriminação não as prive desse espaço aí que é público e que deve ser utilizado por qualquer pessoa, independente da sua orientação ou identidade de gênero a gente também faz esse tipo de articulação. Um exemplo que a gente dá é o do Parque Municipal, em que o público tem enfrentado algumas questões de LGBTfobia, pelo uso do banheiro ou pelo fato de circular e que a gente intervém nesse sentido para qualificar esse atendimento e permitir que ela circule nesse espaço (E2).

É importante ressaltar que foi apontada uma separação do acesso aos bens culturais e espaços de lazer decorrente de processos excludentes de nossa sociedade, que, segundo Monteiro (2009), são espaços condicionados às normas sociais. Acreditamos que essa intervenção que garante à população acesso a esses espaços de lazer pode ser vista como uma política pública de lazer, uma vez que atende à necessidade de promover ações que não enquadrem a minoria às regras da sociedade, mas que, pelo contrário, garantam a multiplicidade dos sujeitos.

No caso da DLGBT, algumas políticas foram mencionadas, entre elas o apoio aos eventos em comemoração aos meses da visibilidade bissexual, lésbica, trans e o apoio à semana do dia 17 de maio, durante a qual, ocorre uma série de eventos que a coordenadoria ajuda a promover. $\mathrm{O}$ entrevistado apontou para o apoio na realização da Parada LGBT, que seria o evento de maior expressão, tendo a última edição, ocorrida em julho deste ano, contado com a presença de 150 mil participantes.

O profissional mencionou também os três eixos de atuação da Coordenadoria, que são: a intersetorialidade, o apoio aos movimentos sociais e as formações. Dentro do eixo de intersetorialidade, há uma "parceria" com a Secretaria Municipal de Esporte e Lazer (SMEL), que promove, no momento, uma articulação junto à Fundação de Parques para a disponibilização de espaços para a realização de atividades de esporte e lazer para meninas lésbicas. Além disso, existem outras duas atividades previstas, uma delas é a realização de uma "Gaymada" dentro do programa da SMEL chamado $B H$ é da gente, que ocorre na Praça Diogo de Vasconcelos ${ }^{3}$, conhecida como Praça da Savassi. A outra é a realização de apoio a um evento privado: uma

\footnotetext{
${ }^{3}$ A Praça Diogo de Vasconcelos está localizada no bairro Funcionários na cidade de Belo Horizonte, região também conhecida como Savassi, fazendo com que a praça também seja popularmente reconhecida como Praça da Savassi.
} 
caminhada que irá ocorrer em torno do Mineirão e abrangerá as questões LGBT. Por fim, o profissional aponta para o fato de essas políticas terem um caráter pontual.

Os profissionais ressaltaram que não é responsabilidade do seu órgão promover as atividades de lazer para a população LGBT, que essas ações deveriam promovidas pela e que o que eles poderiam realizar, portanto, é a articulação:

\begin{abstract}
Pode ser um apoiador e da promoção na questão do lazer, um apoiador no sentido de como a gente apoiou as meninas lésbicas no futebol, que elas precisavam do espaço, precisavam de uma articulação, que abrisse um espaço de diálogo para que elas pudessem fazer o lazer delas naquele momento que era um evento específico, mas que parece que depois elas continuam. Então assim, eu tenho que entender que as diretorias principalmente que acompanham essas secretarias de direitos e cidadania, elas não são executoras de ação diretas, no sentido de políticas públicas. Eu não executo política pública de saúde, eu não executo políticas pública de assistência, eu não executo política pública de esporte e lazer. Então eu não ofereço futebol para as meninas, eu não ofereço o vôlei dos meninos, então a gente tem o vôlei dos que meninos que participam muitos gays, eu não ofereço essas atividades diretamente, mas eu posso entrar, por exemplo, dentro da SMEL e pautar, por exemplo, ações para o público LGBT e dizer da importância e posso inclusive monitorar se eles estão executando algo desta política (E2).
\end{abstract}

Apesar dessa indicação de que a responsabilidade da coordenadoria seria somente em pautar a necessidade das políticas de lazer junto à SMEL, os entrevistados não apontam se isso de fato ocorre, ou seja, não há como afirmar se esses profissionais estão propondo essa articulação com a SMEL. Além disso, cabe uma discussão em relação à não responsabilidade da coordenadoria em desenvolver as ações, mas apenas pautar e monitorar se as ações estão sendo executas pelas secretarias setoriais. Essa discussão é importante, tendo em vista que, o Plano de Trabalho da própria coordenadoria, documento a que foi tido o acesso, aponta que o "objetivo estratégico" da coordenadoria seria a:

Elaboração e implementação de políticas públicas que visem ao combate à discriminação por orientação sexual e identidade de gênero, promovam e garantam os direitos humanos e a cidadania de gays, lésbicas, bissexuais, travestis e transexuais em Belo Horizonte (BELO HORIZONTE, [ca 2017]).

Sendo assim, a responsabilidade da execução de ações que promovam o acesso aos direitos sociais, entre eles o lazer, não deva ser de exclusividade das secretarias setoriais. Assim como apontado no Plano de Trabalho dessa coordenadoria, também deveria ser uma das atribuições desse órgão a elaboração e implementação de políticas públicas que visem à promoção e garantia dos direitos.

Em relação às atividades desenvolvidas pela Coordenadoria Estadual, foram citadas ações como o Cinema em Cores, realizada em parceria com a Secretaria de Estado de Cultura (SEC), a 
Semana da Diversidade Sexual, comemorando o dia 17 de maio, em que ocorreram atividades na própria Cidade Administrativa (onde está localizada a Coordenadoria), como a realização de um "Cinema Comentado" e uma "Apresentação de Drag Queens". Além disso, foi apontado que, nessa semana, ocorreram outras atividades na cidade que culminaram na Parada LGBT, citada pelos entrevistados como uma atividade que a Coordenadoria Estadual apoia. Por fim, foi indicada a parceria em concursos de miss, inclusive dentro do sistema prisional, e parcerias em promoção de shows. No entanto, assim como ocorreu na Coordenadoria Municipal, houve indicação para o fato de essas políticas serem pontuais por dois dos profissionais entrevistados desta coordenadoria.

Sendo assim, foi constatado que, atualmente, ambos os órgãos estudados promovem atividades de acesso ao lazer. No entanto, é possível perceber que essas ações de lazer identificadas possuem características de cunho temporal e pontual, assim como reconhecido pelos próprios profissionais. Nesse ponto, ressaltamos o entendimento das ações temporais, como aquelas ações de caráter ocupacional, denominadas por Bramante (1997) como "política de eventos", e as pontuais como aquelas ações que não carregam em si um “objetivo-fim”, sendo assim políticas paliativas para determinadas situações e que não transformam a realidade.

Nesse sentido, o predomínio de ações pontuais dificulta a possibilidade de uma emancipação e inserção social da população LGBT por meio do lazer. Esses achados vão ao encontro dos resultados da pesquisa de Isayama (2014), em que as políticas de lazer que foram encontradas foram, em sua maioria, atividades que não conseguem trazer à sua aplicação reflexos sociais capazes de combater as desigualdades sociais.

Outro ponto importante foi o aparecimento de um conflito dos próprios profissionais se algumas de suas ações teriam de fato como objetivo o lazer ou se seriam ações de caráter político, ou seja, havia dúvida se um evento que tinha também uma característica de reivindicação social poderia ser considerado lazer. Nesse sentido, verificamos uma dificuldade de alguns dos profissionais em estabelecer se algumas das ações executadas são de fato provedoras do lazer ou se seriam apenas uma política pública com outros objetivos, como se a política não pudesse estar dentro de um momento de lazer, notando-se, assim, uma dicotomia entre o lazer e a política.

Tavares (2011) destaca que é preciso construir um entendimento mais abrangente do lazer, em que a possibilidade de atrelá-lo à discussão política é algo legítimo:

Destaco aqui a necessidade de um entendimento mais amplo acerca das potencialidades do lazer, principalmente no que tange a seu duplo aspecto educativo. Ou seja, o lazer é sim um veículo de educação, por isso atrelá-lo ao campo da discussão política é uma possibilidade real. Ao mesmo tempo, torna-se fundamental uma educação para o lazer (lazer, objeto de educação), que parte da 
conscientização deste como direito à reivindicação desse direito (TAVARES, 2011, p. 148).

Quando perguntado aos entrevistados sobre os profissionais que são responsáveis pelo desenvolvimento dessas ações de lazer, na Coordenadoria Municipal, foi indicado que seria melhor que esta pergunta fosse feita para a SMEL, mas, de forma geral, ficou subentendido que não existe um profissional específico para a elaboração de atividades que tenham como temática o lazer. No caso da Coordenadoria Estadual, ficou evidente que não existe profissional específico para lidar com essa demanda, que as atividades que são realizadas dentro da temática são desenvolvidas pelo grupo dos profissionais que ali atuam e que a divisão das tarefas para o desenvolvimento e realização dessas ações é organizada por afinidade.

Um fato interessante que apareceu foi que, após a realização de todas as perguntas, quando foi aberto um espaço para que os profissionais acrescentassem algo que eles gostariam de falar a mais, esse assunto voltou à tona em duas das entrevistas, em que os sujeitos mencionaram que seria importante repensar como estão sendo organizadas essas atividades de lazer por eles e, inclusive, um dos entrevistados apontou que seria interessante que eles tivessem algum profissional que pudesse trabalhar diretamente com o desenvolvimento dessas ações. Percebemos o entendimento desses profissionais acerca de uma possível atuação de um profissional que tenha conhecimentos sobre a temática do lazer no "assessoramento" do desenvolvimento e execução das ações de lazer do órgão público.

Nesse sentido, é importante a reflexão sobre as inúmeras possibilidades que possui um profissional do lazer em sua atuação e que, para que essas possibilidades sejam de fato concretizadas, ou seja, para que esses profissionais possam inserir-se nesses campos de atuação, há que se pensar em "propostas ou fundamentos que possam orientar a intervenção profissional na área do lazer em nosso contexto sociocultural mais amplo" (TAVARES, 2011, p.83).

\section{O lazer e a importância da sua promoção na visão dos profissionais}

Sobre o segundo eixo, iniciamos com o entendimento dos profissionais entrevistados em relação à promoção do lazer: se esta deveria ser uma função ou uma prioridade para o desenvolvimento de políticas públicas do órgão. Essa pergunta gerou, durante a maioria das entrevistas, tensão no momento de elaboração da resposta. Isso porque alguns profissionais pareciam não ter concretizado uma argumentação sobre essa indagação. Sendo assim, houve momentos em que as falas foram mudando de percurso, ao longo da elaboração da resposta pelo entrevistado, como podemos perceber na construção das falas a seguir: 
O Centro de Referência acho que ficou claro, porque inclusive está com uma das notas que as pessoas procuram, o acesso a cultura e ao lazer. É prioridade e é nossa função também, quer dizer, que essas políticas aconteçam (E2).

A gente tem tantos direitos ainda que não são garantidos, imagina até chegar no lazer, que pra sociedade não é tão primordial entre aspas, não é tão prioridade. Tem direitos básicos que é uma vida e que não são garantidos (E2).

Foi identificado, no início do discurso deste profissional, um apontamento de que o lazer seria uma das prioridades da Coordenadoria, através de articulações que garantam o acesso ao lazer para essa população. No entanto, em seguida, o entrevistado afirma que há outros direitos que ainda não foram garantidos e que, por isso, o lazer não seria prioridade, uma vez que, para a sociedade, ele não seria “tão primordial”. Há nessa fala uma espécie de hierarquização dos direitos sociais, em que o lazer não seria uma prioridade.

Em seguida, o profissional se justifica, utilizando como exemplo a situação da população trans, afirmando que são pessoas que ainda lutam pela sobrevivência, devido ao alto nível de violência que sofre essa população no Brasil. Esse mesmo argumento é utilizado por outro profissional:

Eu diria que a gente ainda não teve tempo de se preocupar com isso, eu gostaria que fosse um futuro bem próximo, mas assim, enquanto ainda tem, muitos travestis, por exemplo, morrendo por aí, enquanto tem muita discriminação no setor público de saúde, enquanto tem muita discriminação pra empregar pessoas trans, por exemplo, ou qualquer um da população LGBT, a gente não teve tempo de pensar nessa questão do lazer. Mas é claro, ela não é prioridade, ela é importante. Eu acho que aqui se pensa, mas talvez muito pouco, muito menos do que se deveria pensar, porque não deu tempo ainda, infelizmente por isso, tem outras prioridades, temos que garantir a sobrevivência. $O$ dia que chegar o momento que falar, não tem perigo nenhum, não existe discriminação e ninguém tá morrendo por causa de sua orientação sexual ou por causa da sua identidade de gênero, ninguém ta sendo discriminado, então agora a gente pode pensar no lazer (E4).

Há ainda a afirmação de um terceiro profissional, que acredita que o lazer é importante, mas aponta que não é uma prioridade da Coordenadoria:

Não, prioridade eu acho que não, ao lazer, eu acho que é mais mesmo nessa questão de visibilidade e respeito, pro pessoal. Agora o lazer eu acho importante também, igual eles fazem a parada, junta o lazer com essas questão que eu falei, é importante sim, mas eu acho que não é o foco principal (E6).

Sobre isso, é importante que reportemos ao que disse Marcellino et al. (2007, p. 14) sobre a existência de uma "baixa ressonância social do lazer, motivada pela forte influência da moral cristã do trabalho, pela aceitação predominante dos valores de produtividade, e pela falsa noção de hierarquização de necessidades humanas". Alves Júnior e Melo (2003) também apontam para essa 
escala hierárquica de necessidades humanas, em que o lazer seria menos importante do que necessidade tais como a educação e a saúde. Os autores apontam que essas seriam de fato dimensões fundamentais, mas que caberia o questionamento de por que o lazer seria menos importante.

Diante disso, questionamos: esse processo de hierarquização que coloca o lazer como um direito a ser discutido após a garantia de outros direitos, conforme indicado pelos entrevistados, não estaria submetendo esses sujeitos a uma continuidade ou agravamento de um processo que os marginaliza? Segundo Gomes, Lacerda e Pinheiro (2010, p.37):

A concretização dos direitos sociais é essencial para o exercício da cidadania plena, uma vez que são imprescindíveis para uma vida digna e dotada de bem-estar. A falta de acesso a este grupo de direitos é responsável pelo surgimento e/ou acentuação das disparidades sociais, uma vez que privam boa parte da população de desfrutar possibilidades que são suas por direito e devem estar à disposição da coletividade.

Menicucci (2006, p.140) nos lembra de que "a emergência dos direitos sociais tem como consequência a responsabilidade do poder público por meio da garantia e da provisão de políticas sociais", sendo, portanto, importante que o poder público priorize também o lazer dentro de um planejamento de ações e políticas públicas que vão atender a uma população que possui os mais diversos direitos negados.

Vale ressaltar uma fala de uma das profissionais que faz relação do uso do nome social com o lazer:

Eu penso que, a população LGBT tem que estar inserida naquilo que lhe é de direito e o lazer e a cultura também é necessária. E eu vou te contar uma coisa curiosa que quando eu ainda estava no movimento social, trabalhando principalmente na alteração de nome para as pessoas trans, uma das preocupações maiores que as meninas tinham era de ir numa boate e apresentar a sua identidade com o nome feminino, o nome que corresponde a imagem dela, ou seja, até para o acesso ao lazer a questão do nome é um constrangimento, quando a gente fala só da saúde, da educação, não, para o lazer também (E5).

O desenvolvimento de políticas públicas de lazer para uma minoria social não deveria ser secundarizada. As ações que visam promover os direitos sociais dessa e de outras populações podem ser realizadas sob a ótica da "intersetorialidade", que, conforme apontado por Menicucci (2006, p. 147), "tem sido definida como uma nova maneira de abordar os problemas sociais, enxergando o cidadão na sua totalidade e estabelecendo uma nova lógica para a gestão da cidade".

A secundarização do direito de acesso ao lazer, corrobora com o estudo de Silveira (2010), que identificou haver uma necessidade de se ampliar a visibilidade e o debate sobre o lazer dentro da agenda política urbana da cidade. 
No entanto, há que se realizar uma contraposição à essa crítica sobre a secundarização do direito ao lazer. Isso porque, o que se percebe é que há incapacidade do poder público e, consequentemente, de seus gestores de suprir todas as demandas da sociedade, tendo em vista, principalmente, à insuficiência de recursos destinadas às determinadas áreas da política social. Nesses casos, o que fica claro na fala dos gestores entrevistados é a necessidade de tomar decisões diante as realidades postas, sobre um público que, muitas vezes, ainda se encontra em situação de vida ou morte. Nesse sentido, o que se percebe é a prevalência de políticas de subsistência dessas populações.

Por fim, um dos profisssionais disse acreditar que o lazer deve ser uma função prioridade de sua coordenadoria, citando, o fato de o lazer ser um direito social garantido pela Constituição de 1988:

Eu acho sim que seria importantíssimo, principalmente para uma Secretaria de direitos humanos, e para coordenação LGBT também, ter o lazer como um de seus princípios, a promoção de lazer, porque quando você fala de direitos humanos, o lazer tá garantido pela constituição (E3).

Sendo assim, há divergências na percepção dos profissionais sobre o lugar do lazer na realização políticas públicas para a população LGBT.

Em relação ao conceito de lazer por parte dos profissionais, a partir de leituras das respostas dos seis profissionais, identificamos quatro perspectivas sobre a questão: 1) o lazer como direito social; 2) o lazer como "objeto-meio"; 3) o lazer como política; e 4) o lazer como um momento de fuga do trabalho. Dois profissionais foram categóricos ao afirmar o lazer como direito social e não se alongaram sobre esse conceito. No entanto, um deles, em continuidade a resposta, caracterizou também o lazer como um "objeto-meio" para a questão da saúde:

Acho que ele tem uma função de socializador, tem uma função de promover saúde, acho que pela ótica da nossa secretaria, do nosso trabalho é direito. E eu acho importantíssimo pra saúde principalmente (E2).

Essa concepção de lazer pode afastá-lo da sua posição como direito social. Ressaltamos que entendemos que não há problemas em se ter como objetivo em uma política pública de lazer a promoção da saúde. No entanto, é fundamental que, em meio às discussões sobre o lazer, principalmente no que diz respeito a sua elaboração e implementação por meio de órgãos públicos, o lazer seja também tido somente como objeto-fim.

Além disso, essa fala que associa o lazer a outro fenômeno pode ter relação sobre o não estabelecimento de um critério definido acerca do lazer e sua importância. Segundo Marcellino (1996), verifica-se na denominação dos órgãos públicos, o acréscimo de palavras ao lazer, tais 
como "esporte e lazer", "turismo e lazer" e "cultura e lazer". Nesse sentido, o que se percebe é uma retirada do protagonismo do lazer, como se ele não se justificasse.

Essa concepção sobre o lazer aparece somente na fala de um dos entrevistados, tendo a maioria dos profissionais, se referido ao lazer como uma questão política. Sobre essa concepção, há que se afirmar a existência da conexão entre esses dois fenômenos, entendendo assim que o lazer possui, sim, uma relação com a política.

Contudo, acreditamos ser importante apontar para a possível existência de uma linha tênue entre o entendimento do lazer como política e a relação do lazer com caráter assistencialista. Percebemos, nas falas, expressões que o caracterizam como uma ferramenta "socializadora", "de promoção à saúde", de "quebra de paradigmas", como "ferramenta de inclusão e "promoção da visibilidade". Nesse sentido, é necessário um cuidado para que as políticas de lazer não se deparem com o que chamou Melo (2009) de "novo assistencialismo crítico"4

Por fim, o lazer foi destacado como momento de fuga do trabalho, em que os sujeitos buscam se recuperar dos males advindos do trabalho. Para essa análise, trazemos as discussões de Marcellino (1996), quando aponta a influência da Igreja Católica sobre a concepção de lazer, reduzindo-o a um complemento ou compensação do trabalho desgastante. Para o autor, ressalta que “'descansar, 'recuperar as energias', distrair-se, entreter-se, recrear-se, enfim, o descanso e o divertimento são os valores comumente mais associados ao lazer" (p. 13).

Marcellino (1996) indica a necessidade de se ter determinado cuidado, ao assimilarmos o lazer como um meio para alívio de tensões ou até mesmo como um facilitador para a convivência com as injustiças sociais, levando à utilização do lazer como uma espécie de fuga e tornando-o fonte de alienação e simples consumo.

Portanto, foi identificado que, há entre os profissionais, visões distintas acerca do lazer, mas, ao mesmo tempo, há algumas concepções que se alinharam, o que foi apontado também pelo estudo de Tavares e Isayama (2014), que indicou que, embora as concepções de lazer encontradas tenham sido caracterizadas de diferenciadas formas, a caracterização do lazer como uma não ocupação/obrigação, por exemplo, foi um ponto que se aproximou nas concepções dos sujeitos.

Percebemos que a realização dessas entrevistas pôde gerar pontos importantes de discussões sobre a contextualização do lazer dentro do planejamento e execução de políticas públicas para a população LGBT. No entanto, as questões levantadas neste estudo são cabíveis de outras discussões, para que se possa de incluir, na agenda dos órgãos públicos que promovem o acesso aos

\footnotetext{
4 "O que as desencadeia é uma suposta visão crítica, um discurso aparentemente bastante "engajado", mas a prática configura-se, não poucas vezes, como uma recriação do velho assistencialismo, marcado por um caráter explicitamente funcionalista" (MELO, 2009, p.26).
} 
direitos sociais da população LGBT, como também para outras minorias sociais, um maior debate sobre o lazer e a importância da sua promoção.

\section{CONSIDERAÇÕES FINAIS}

Em relação à identificação das políticas de lazer desenvolvidas pelos órgãos estudados, foi verificado que, apesar de ter sido constatada a existência de ações promovidas no âmbito do lazer, essas ações parecem ser de cunho pontual e temporal. As ações promovidas pelos órgãos estudados são geralmente eventos esporádicos, de caráter ocupacional, que não carregam em si a capacidade de transformar a realidade, o que talvez impossibilite que essas atividades promovam uma emancipação e inserção social da população LGBT por meio do lazer.

Ressaltamos duas visões sobre a identificação do lazer da população LGBT: a primeira como ato de resistência política, que opôs-se à compreensão que separa lazer e política. Outro ponto com destaque foi a não percepção do lazer como direito social, pois não é visualizado como elemento imprescindível para o bem-estar e para a constituição de uma cidadania dos sujeitos.

Destacou-se, ainda, a percepção do lazer como direito secundário, ainda que ele esteja estabelecido em nossa Constituição de 1988 como direito social no mesmo patamar dos demais. Apesar de termos consciência da limitação do poder público e da sua necessidade em tomar decisões devido à insuficiência de recursos, alertamos que secundarização desse direito pode levar à continuidade de um processo de marginalização, não somente da minoria estudada, como também das demais minorias sociais.

Outro aspecto constatado foi a relação do lazer como uma dimensão compensatória do trabalho, que, entre as concepções que viam o lazer como algo de caráter libertador, desinteressado e hedonístico, traz implicitamente uma visão do lazer como um meio para o alívio das tensões geradas pelo cotidiano e pelo trabalho. Não entendemos como algo problemático a visão de um lazer ligado ao descanso, ao relaxamento, à distração de uma rotina, muitas das vezes estressantes, na qual estamos inseridos, afinal, o lazer é sim composto por tudo isso. No entanto, a crítica que aqui se levanta é quanto ao cuidado que se deve ter para que essas concepções não tornem o lazer algo alienador, reduzindo-o ao consumo, que desconsidera sua capacidade de formação crítica do ser humano e de emancipação dos indivíduos. 


\section{REFERÊNCIAS}

$3^{\text {a }}$ CONFERÊNCIA NACIONAL DE POLÍTICAS PÚBLICAS E DIREITOS HUMANOS DE LÉSBICAS, GAYS, BISSEXUAIS, TRAVESTIS E TRANSEXUAIS, 3., 2016. Relatório Final. Brasília, Distrito Federal. Ministério da Mulheres, da Igualdade Racial, da Juventude e dos Direitos Humanos, Abril de 2016. p. 1-126.

$3^{\text {a }}$ CONFERÊNCIA ESTADUAL DE POLÍTICAS PÚBLICAS E DIREITOS HUMANOS DE LGBT, 3., 2015, Belo Horizonte. Relatório de propostas. Belo Horizonte, Minas Gerais: Secretaria de Direitos Humanos, Participação Social e Cidadania, Outubro de 2015. p. 1-11.

ALVES JÚNIOR, Edmundo de Drummond; MELO, Victor Andrade de. Introdução ao lazer. Barueri: Manole, 2003.

AMARAL, Thiago Clemente. Travestis, transexuais e mercado de trabalho: muito além da prostituição. III Seminário internacional enlaçando sexualidades. Salvador, 2013. p. 1-13.

BARDIN, Laurence. Análise de conteúdo. Lisboa: Edições 70, 2010.

BELO HORIZONTE. Secretaria Municipal de Políticas Sociais - Secretaria Adjunta de Direito e Cidadania. Plano de Trabalho Coordenadoria dos Direitos da População LGBT. Belo Horizonte: Secretaria Municipal de Políticas Sociais, [ca 2017].

BRASIL, Constituição (1988). Constituição da República Federativa do Brasil: atualizada até 20.09.2007. Disponível em: http://www.senado.leg.br/atividade/const/constituicao-federal.asp\#. Acesso em: 23 de abril de 2018.

BRAMANTE, Antônio Carlos. Qualidade no gerenciamento do lazer. In: BRUHNS, Heloísa Turini (Org.). Introdução aos estudos do lazer. Campinas: Editora UNICAMP, 1997. p. 123-141.

CANABARRO, Ronaldo. História e direitos sexuais no Brasil: o Movimento LGBT e a discussão sobre a cidadania. Anais eletrônicos do II Congresso Internacional de História Regional. Passo Fundo, 2013. p. 1-15.

CURY, Carlos Roberto Jamil. Dimensões políticas do lazer: lazer, cidadania e responsabilidade social. Brasília: UniSesi, 2006.

FAZZANO, Leandro; GALLO, Alex. Uma Análise da Homofobia Sob Perspectiva da Análise de Comportamento. Temas em Psicologia, Sociedade Brasileira de Psicologia. Ribeirão Preto, v.23, n.3, p. 535-545, setembro de 2015.

GOELLNER, Silvana V.; VOTRE, Sebastião Josué; MOURÃO, Ludmila; FIGUEIRA, Marcia Luiza Machado. Gênero e raça: inclusão no esporte e lazer. Porto Alegre. Ministério do Esporte e Gráfica da Universidade Federal do Rio Grande do Sul, 2009. p. 3-20.

GOMES, Christiane; LACERDA, Leonardo; PINHEIRO, Marcos. Lazer, turismo e inclusão social. Intervenção com idosos. Belo Horizonte. Editora UFMG, 2010. 
LUNARDI, Alexandre. A proteção jurídica do tempo de lazer. In: GOMES, Christianne Luce; ISAYAMA, Hélder Ferreira (Org.). O direito social ao lazer no Brasil. Campinas. Autores Associados, 2015. p. 201-227.

MARCELLINO, Nelson Carvalho. Estudos do lazer: uma introdução. Campinas. Autores associados, 1996.

MARCELLINO, Nelson Carvalho. Lazer e esporte: políticas públicas. Campinas. Autores Associados, 2001. p 5-29.

MARCELLINO, Nelson Carvalho. Lazer e Sociedade: algumas aproximações. In: MARCELLINO, Nelson Carvalho (Org.). Lazer e Sociedade. Múltiplas Relações. Campinas. Alínea, 2008. p. 11-26.

MARCELLINO, Nelson Carvalho; SAMPAIO, Tânia Mara Vieira; CAPI, André Henrique Chabaribery. Políticas públicas de lazer: formação e desenvolvimento de pessoal. OPUS, 2007.

MELO, Victor Andrade de. Lazer e minorias sociais. São Paulo, SP. IBRASA, 2003, p. 21 - 28.

MELO, Victor Andrade de. Lazer como ferramenta de ação social: ponderações. In: MONTEIRO, Mônica; DIAS, Cleber Augusto Gonçalves (Org.). Lazer e periferia. Um olhar a partir das margens. São Gonçalo. Instituto Usina Social, 2009. p. 23-41.

MENICUCCI, Telma. Políticas públicas de lazer: questões analíticas e desafios políticos. In: ISAYAMA, Hélder Ferreira; LINHALES, Meily Assbú (Org.). Sobre lazer e política: maneiras de ver, maneiras de fazer. Belo Horizonte. Editora UFMG, 2006. p.136-164.

MONTEIRO, Mônica As relações entre a ocupação dos espaços públicos de lazer e as territorialidades. In: MONTEIRO, Mônica ; DIAS, Cleber Augusto Gonçalves (Org.). Lazer e Periferia. Um olhar a partir das margens. São Gonçalo. Instituto Usina Social, 2009. p. 93-101.

PINTO, Leila Mirtes Santos de Magalhães. Políticas Públicas de Lazer no Brasil: uma história a contar. In: MARCELLINO, Nelson Carvalho (Org). Políticas públicas de lazer. Campinas. Alínea, 2008. p 79-95.

RAEDER, Savio. Ciclo de políticas: uma abordagem integradora dos modelos para análise de políticas públicas. Perspectivas em Políticas Públicas. Belo Horizonte, v. 7, n. 13, p. 121-146, jan/jun 2014.

SANTOS, Flávia da Cruz; AMARAL, Sílvia Cristina Franco. Sobre o lazer e as políticas sociais: questões teórico-conceituais. Pensar a prática, Goiânia, v. 13, n. 3, p. 1-13, setembro/dezembro de 2010 .

SILVA, Débora Alice Machado. O lazer como campo: desafios à concretização do direito social em um Brasil "em construção" democrática. In: GOMES, Christianne Lucce; ISAYAMA, Hélder Ferreira (Org.) O direito social ao lazer no Brasil. Campinas. Autores Associados, 2015. p. 157182.

SILVA, Glauber Weder dos Santos; SOUZA, Emanoel Fhilipe Leite; SENA, Romeika Carla Ferreira de; MOURA, Izabella Bezerra de Lima; SOBREIRA, Maura Vanessa Silva; MIRANDA, Francisco Arnoldo Nunes de. Situações de violência contra travestis e transexuais em um município 
do nordeste brasileiro. Revista Gaúcha de Enfermagem, Porto Alegre, v. 37, n.2, p. 1-7, junho de 2016.

SILVEIRA, Amanda Carolina Costa. Um olhar sobre a política urbana de Belo Horizonte: há espaço para o lazer dentro do planejamento urbano? Tese (Mestrado em Estudos do Lazer) - Escola de Educação Física, Fisioterapia e Terapia Ocupacional, Universidade Federal de Minas Gerais.

Belo Horizonte, Março de 2010.

SOUZA, Celina. Políticas Públicas: uma revisão da literatura. Sociologias. Porto Alegre, ano 8, n. 16, p. 20-44, julho/dezembro de 2006.

SOUZA, Flávia Faissal de Souza. Estrutura Política Excludente, Práticas Culturais Normalizadoras, Políticas de Alívio à Pobreza: o lazer em questão. In: MARCELLINO, Nelson Carvalho (Org.).

Lazer e Sociedade. Múltiplas Relações. Campinas. Alínea, 2008. p. 121-137.

TAVARES, Marie Luce; ISAYAMA, Hélder Ferreira. Na parada do lazer: delineando as ações de lazer em ONGs LGBT de Belo Horizonte. Revista Brasileira de Educação Física e Esporte, 28(4), 579-597, 2014.

TAVARES, Marie Luce. Na parada do lazer: diagnóstico do campo de atuação profissional nas ONGs LGBT de Belo Horizonte/MG. Tese (Mestrado em Estudos do Lazer) - Escola de Educação Física, Fisioterapia e Terapia Ocupacional, Universidade Federal de Minas Gerais. Belo Horizonte, Maio de 2011.

\section{NOTAS DE AUTOR}

AGRADECIMENTOS - Não se aplica.

CONTRIBUIÇÃO DE AUTORIA - Não se aplica.

FINANCIAMENTO = Não se aplica.

CONSENTIMENTO DE USO DE IMAGEM - Não se aplica.

APROVAÇÃO DE COMITÊ DE ÉTICA EM PESQUISA - Não se aplica.

CONFLITO DE INTERESSES - Não há conflitos de interesse.

\section{LICENÇA DE USO}

Os autores cedem à Motrivivência - ISSN 2175-8042 os direitos exclusivos de primeira publicação, com o trabalho simultaneamente licenciado sob a Licença Creative Commons Attribution Non-Comercial ShareAlike (CC BY-NC SA) 4.0 International. Esta licença permite que terceiros remixem, adaptem e criem a partir do trabalho publicado, desde que para fins não comerciais, atribuindo o devido crédito de autoria e publicação inicial neste periódico desde que adotem a mesma licença, compartilhar igual. Os autores têm autorização para assumir contratos adicionais separadamente, para distribuição não exclusiva da versão do trabalho publicada neste periódico (ex.: publicar em repositório institucional, em site pessoal, publicar uma tradução, ou como capítulo de livro), com reconhecimento de autoria e publicação inicial neste periódico, desde que para fins não comerciais e compartilhar com a mesma licença. 


\section{PUBLISHER}

Universidade Federal de Santa Catarina. Programa de Pós-Graduação em Educação Física. LaboMídia - Laboratório e Observatório da Mídia Esportiva. Publicado no Portal de Periódicos UFSC. As ideias expressadas neste artigo são de responsabilidade de seus autores, não representando, necessariamente, a opinião dos editores ou da universidade.

\section{EDITORES}

Mauricio Roberto da Silva, Giovani De Lorenzi Pires, Rogério Santos Pereira.

\section{HISTÓRICO}

Recebido em: 17 de fevereiro de 2020.

Aprovado em: 14 de abril de 2020. 